\title{
Making the upper edge of a silicone breast implant invisible by fat onlay-grafting harvested from the affected inframammary fold
}

\author{
Naohiro Ishii ${ }^{1}$, Michiko Harao ${ }^{2}$, Tomoki Kiuchi ${ }^{1}$, Shigeki Sakai ${ }^{3}$, Takahiro Uno ${ }^{3}$, Jiro Ando ${ }^{4}$, \\ Kazuo Kishi ${ }^{3}$
}

${ }^{1}$ Department of Plastic and Reconstructive Surgery, International University of Health and Welfare Hospital, Tochigi, Japan; ${ }^{2}$ Department of Breast Surgery, Jichi Medical University, Tochigi, Japan; ${ }^{3}$ Department of Plastic and Reconstructive Surgery, Keio University, Tokyo, Japan; ${ }^{4}$ Department of Breast Surgery, Tochigi Cancer Center, Tochigi, Japan

Contributions: (I) Conception and design: N Ishii; (II) Administrative support: K Kishi; (III) Provision of study materials or patients: J Ando, M Harao;

(IV) Collection and assembly of data: N Ishii; (V) Data analysis and interpretation: S Sakai, T Uno, T Kiuchi; (VI) Manuscript writing: All authors;

(VII) Final approval of manuscript: All authors.

Correspondence to: Naohiro Ishii, MD, PhD. Department of Plastic and Reconstructive Surgery, International University of Health and Welfare Hospital, 537-3 Iguchi, Nasushiobara City, Tochigi 329-2763, Japan. Email: ishinao0916@gmail.com.

Background: In silicone breast implant (SBI)-based breast reconstructions, aesthetic outcomes are often low due to the visible upper edge of the SBI. To ameliorate this, grafting fat harvested from the SBI operative field has not been reported to date. Therefore, we aimed to develop a novel technique for fat onlay-grafting, harvested from the inframammary fold (IMF) of the reconstructed breast, and investigate its usefulness.

Methods: A total of 90 patients who underwent SBI-based breast reconstruction after a simple mastectomy were included in this study. The harvested fat was recorded by weight and grafted evenly to the medial and median upper edge of the SBI on the pectoralis major muscle. We applied this technique to 30 patients (fat onlay-grafting group) and compared them with the 60 patients (no-grafting group) who did not undergo our technique using the postoperative 1-year aesthetic outcome scores of the medial and median upper edge of the SBI. Furthermore, we investigated the correlation between the weight of harvested fat and body mass index.

Results: No postoperative wound complications occurred, and infection, hardened fat, and fat lysis were not found in the fat onlay-grafting group. The medial and total aesthetic outcome scores in the fat onlaygrafting group were significantly higher than those in the no-grafting group $(\mathrm{P}<0.05)$. The average weight of harvested fat was 11.9 [5-32] g. The correlation between the weight of the harvested fat and body mass index was significantly positive $\left(\mathrm{R}^{2}=0.7119, \mathrm{P}<0.05\right)$.

Conclusions: Our technique made the upper edge of the SBI invisible. Further, it was simple and less invasive with safe augmentation. Therefore, we believe that this technique can contribute to better aesthetic outcomes in SBI-based breast reconstruction.

Keywords: Breast reconstruction; breast implant; fat graft; fat onlay-grafting; mastectomy

Submitted Jun 25, 2021. Accepted for publication Jul 30, 2021.

doi: $10.21037 /$ gs-21-425

View this article at: https://dx.doi.org/10.21037/gs-21-425

\footnotetext{
$\wedge$ ORCID: 0000-0001-8838-5344.
} 


\section{Introduction}

Silicone breast implant (SBI)-based breast reconstruction is widely performed and popular for patients because it is less invasive. However, SBI differs from the unaffected breast in texture and elasticity; therefore, the edge of SBI is often visible, and consequently, the presence of artificial material is often conspicuous, particularly in patients with a thin pectoral subcutaneous tissue (1).

Less invasive revision of the visible upper edge of the SBI due to the level of differences and depression remains challenging. Fat injection, in which the donor site is the abdomen or thigh, has been performed to create puffy decolletes in one or two stages; however, donor sites other than the affected chest are required (2-5). Grafting fat harvested from the SBI operative field has not been reported to date.

Our study aimed to investigate the usefulness of fat onlay-grafting to the upper edge of SBI, where the donor site is the subcutaneous tissue of the inframammary fold (IMF) of the reconstructed breast, and determine the contribution of this technique to aesthetic outcomes. We present the following article in accordance with the STROBE reporting checklist (available at https://dx.doi. org/10.21037/gs-21-425).

\section{Methods}

The study was conducted in accordance with the Declaration of Helsinki (as revised in 2013). The study was approved by the ethics committee of the Tochigi cancer center (No. C-248) and informed consent was taken from all the patients.

\section{Patients}

A total of 90 patients who underwent unilateral SBI-based reconstruction following a tissue expander (Natrelle 133; Allergan, Ireland, Dublin) insertion after simple mastectomy were eligible for inclusion in the retrospective cohort study. We used an anatomical and textured SBI (Natrelle 410, True form 3; Allergan, Ireland, Dublin) for the procedures. Patients who underwent radiotherapy were excluded from the study. Among them, 30 patients (fat onlay-grafting group) received fat onlay-grafting to the upper edge of the SBI between May 2017 and June 2019, as described below. In the other 60 patients (no-grafting group), only SBI insertion was performed between September 2014 and April 2017. There were no selection criteria in these two groups other than the operative period. The characteristics of the patients included in this study are shown in Table 1.

\section{Surgical procedure}

SBI insertion following the full expansion of the tissue expander was performed using previous incisions. After cutting the capsule and removing the tissue expander, we performed partial resection by using scissors to cut the caudal subcutaneous tissue to make the caudal skin thin in order to create a clear IMF (Figure $1 A, 1 B$ ). Then, the caudal thin skin was fixed to the chest wall as an IMF using a modified internal method $(6,7)$.

The weight of the resected fat was measured and recorded in the fat onlay-grafting group. In contrast, the resected fat was discarded without measuring its weight in the no-grafting group. The SBI was inserted under the pectoralis major muscle, and its position was controlled with a sitting position (Figure 1C). The harvested fat was entirely onlay-grafted evenly without sutures on the pectoralis major muscle located at the medial and median upper edge of the SBI (Figure 1D). Two suction drains were inserted: one was inserted around the SBI under the pectoralis major muscle, and the other was inserted around the grafted fat to fix it on the pectoralis major muscle (Figure 1E). The latter drain was carefully indwelled to prevent aspiration of the grafted fat. For 6 months after SBI insertion, both breasts were fixed with a controlling brassiere.

\section{Evaluations}

One year after SBI insertion, aesthetic outcomes in the medial and median upper edge of the SBI were evaluated by scoring using Harris's classification: 0, poor; 1, fair; 2 , good (8). The medial, median, and total scores (the sum of the medial and median scores) were recorded. We compared the average of each score between the fat onlay-grafting and no-grafting groups. Additionally, we investigated the correlation between the weight of harvested fat (weight of grafted fat) and body mass index (BMI) in the fat onlay-grafting group. All reconstruction procedures, measurements, and evaluations were performed by the corresponding author. All patients in this study have undergone follow-up to date.

\section{Statistical analysis}

Data were analyzed using SPSS version 23 for Windows 
Table 1 Characteristics of the patients

\begin{tabular}{lcc}
\hline Category & Fat onlay-grafting group & No-grafting group \\
\hline Cases & 30 & 60 \\
Age, mean \pm SD (years) & $45.7 \pm 9.5$ & $48.9 \pm 10.6$ \\
Body mass index, mean \pm SD $\left(\mathrm{kg} / \mathrm{m}^{2}\right)$ & $21.4 \pm 2.7$ & $21.5 \pm 2.6$ \\
Volume of silicone breast implant, mean $\pm \mathrm{SD}\left(\mathrm{cm}^{3}\right)$ & $333.5 \pm 100.2$ & $346.6 \pm 130.4$ \\
\hline
\end{tabular}

$\mathrm{SD}$, standard deviation.
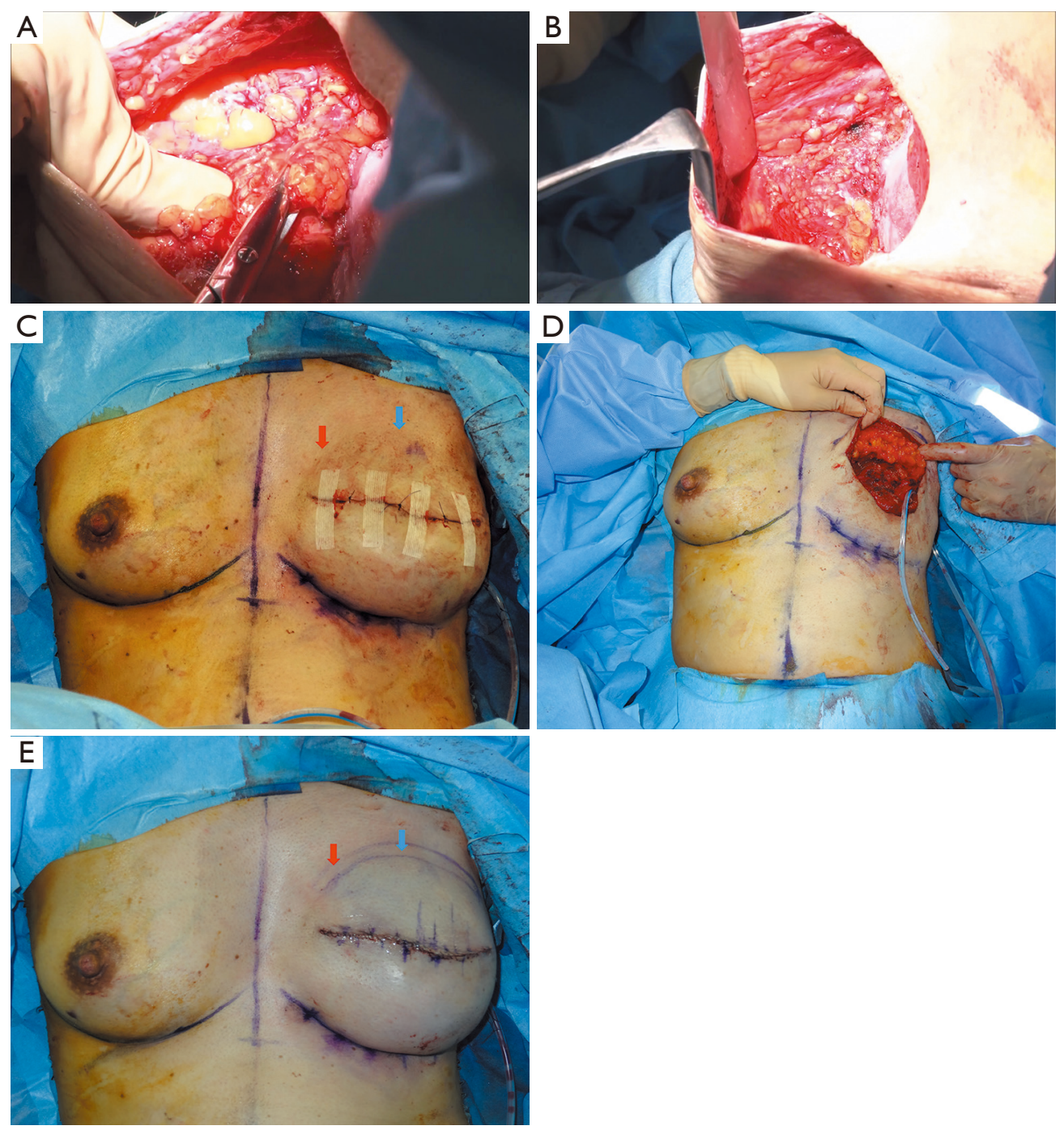

Figure 1 Sequential images of a sample case with undergoing fat onlay-grafting. (A) An image during harvesting fat for onlay-grafting. In creating a fine inframammary fold, the caudal skin is thinned by scissors, and resected fat is preserved for grafting. (B) An image after harvesting fat for onlay-grafting. This caudal thin skin is fixed to the chest wall as an inframammary fold. (C) An image before fat onlaygrafting when the silicone breast implant is set and two suction drains are inserted. The medial upper edge (red arrow) and median edge (blue arrow) of the silicone breast implant are visible. (D) An image of the harvested and grafted fat which was onlaid (weight of harvested graft: $11 \mathrm{~g}$, body mass index: $20.5 \mathrm{~kg} / \mathrm{m}^{2}$ ). (E) An image after fat onlay-grafting when the silicone breast implant is set and two suction drains are inserted. The medial upper edge (red arrow) and median edge (blue arrow) of silicone breast implant become invisible. 
Table 2 Aesthetic outcomes in the upper edge of the silicone breast implant

\begin{tabular}{lccc}
\hline Category & Fat onlay-grafting group & No-grafting group & P value \\
\hline Medial score, mean \pm SD & $1.8 \pm 0.4$ & $1.3 \pm 0.6$ & $<0.05$ \\
Median score, mean \pm SD & $2.0 \pm 0.2$ & $1.9 \pm 0.3$ & 0.31 \\
Total score, mean \pm SD & $3.8 \pm 0.5$ & $3.2 \pm 0.7$ & $<0.05$ \\
\hline
\end{tabular}

$\mathrm{SD}$, standard deviation.

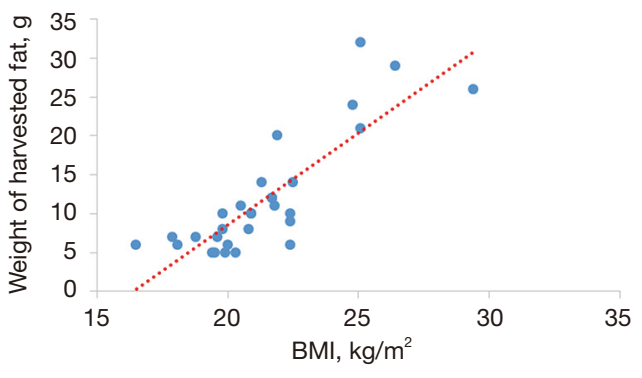

Figure 2 A scatter plot and simple linear regression of weight of harvested fat and body mass index. BMI, body mass index.

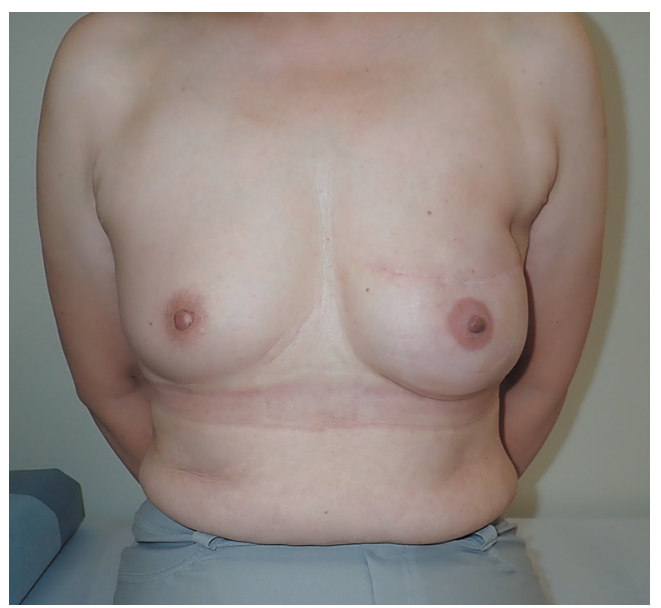

Figure 3 Images at 1 year and 2 months after silicone breast implant operation in the fat onlay-grafting group (age, 62 years; body mass index, $21.8 \mathrm{~kg} / \mathrm{m}^{2}$; volume of silicone breast implant, $280 \mathrm{~cm}^{3}$; harvested graft, $11 \mathrm{~g}$; medial and median aesthetic outcomes score, 2 and 2, respectively). Good aesthetic outcomes have been achieved.

(IBM Corporation, Armonk, NY, USA). A simple linear regression analysis was used to define the linear relationship between the weight of harvested fat and BMI. The student's $t$-test was used to compare the averages of continuous variables between the groups. For all statistical tests, a
$\mathrm{P}$ value of $<0.05$ was considered significant.

\section{Results}

There were no obvious differences in each category between the groups (Table 1). In all cases, no postoperative wound complications occurred. In the fat onlay-grafting group, infection, hardened fat, and fat lysis were not found.

The medial and total scores in the fat onlay-grafting group were significantly higher than those in the nongrafting group $(\mathrm{P}<0.05)$; however, median scores in the fat onlay-grafting group were similar to those in the nongrafting group ( $\mathrm{P}=0.311)$ (Table 2).

The average weight of harvested fat was 11.9 [5-32] g. The simple linear regression analysis showed a significant positive correlation between the weight of harvested fat and BMI (coefficient of determination: $\mathrm{R}^{2}=0.7119, \mathrm{P}<0.05$ ) (Figure 2).

Three patients in the no-grafting group showed poor medial scores; however, no patient in the fat onlay-grafting group showed a poor medial score. Six patients in the fat onlay-grafting group had a fair medial score. Their weight of harvested fat was comparatively low $\{5.8[5-7] \mathrm{g}\}$, and their BMI was slightly low $\left\{20.0[18.1-22.4] \mathrm{kg} / \mathrm{m}^{2}\right\}$. Typical cases are shown in Figures 3-6.

\section{Discussion}

We performed fat onlay-grafting at the upper edge of the SBI, the donor site of which was the caudal subcutaneous tissue of the reconstructed breast for patients undergoing two-stage SBI-based breast reconstruction. Furthermore, we investigated the usefulness of our technique by comparing the aesthetic outcomes in the fat onlay-grafting group with those in the no-grafting group and the correlation between the weight of harvested fat and BMI in each patient. The results showed that the aesthetic outcomes in the fat onlaygrafting group were significantly better than those in the no-grafting group, particularly in the medial upper edge 


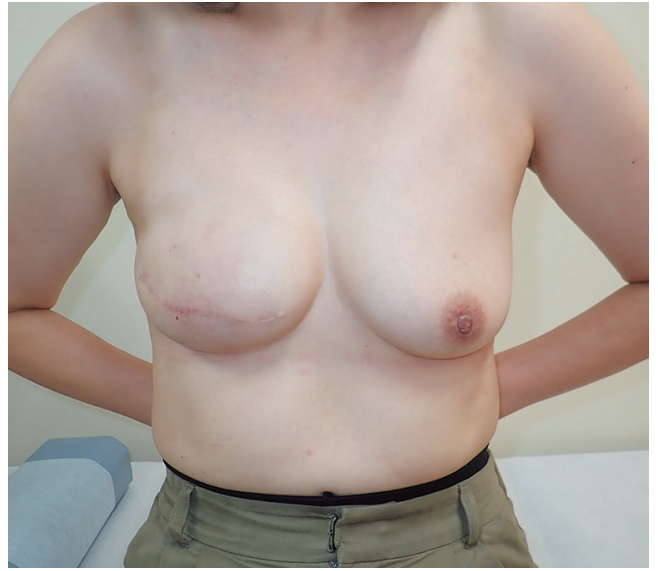

Figure 4 Image at 1 year after silicone breast implant operation in the fat onlay-grafting group (age, 47 years; body mass index, $21.3 \mathrm{~kg} / \mathrm{m}^{2}$; volume of silicone breast implant, $295 \mathrm{~cm}^{3}$; harvested graft, $14 \mathrm{~g}$; medial and median aesthetic outcomes score, 2 and 2, respectively). Good aesthetic outcomes have been achieved.

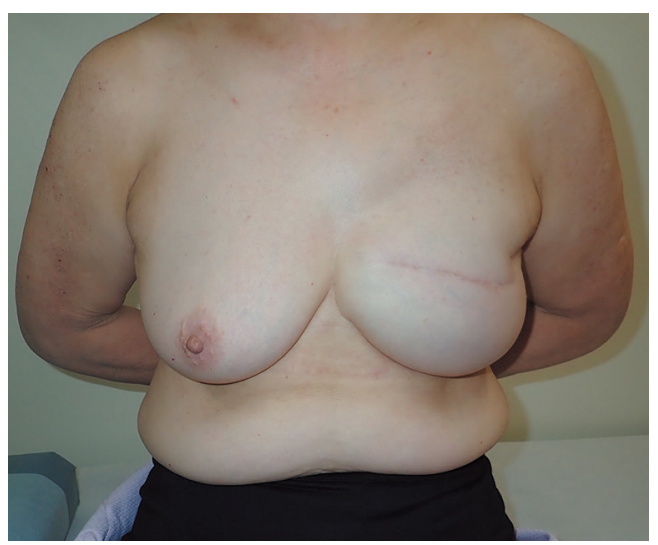

Figure 5 Images at 1 year and 6 months after silicone breast implant operation in the no-grafting group (age, 66 years; body mass index, $24.3 \mathrm{~kg} / \mathrm{m}^{2}$; volume of silicone breast implant, $445 \mathrm{~cm}^{3}$; medial and median aesthetic outcomes score, 0 and 1 , respectively). The concerns regarding the aesthetic outcomes remain. The upper edge of the silicone breast implant is visible.

of the SBI, and the correlation between the weight of harvested fat and BMI was significantly positive.

The common aesthetic concern encountered in SBI-based breast reconstruction is the visible upper edge of the SBI due to the level differences and depression. This is because the SBI differs from the unaffected breast in texture and elasticity and has a thick capsule (1). Further, the height and thickness in the upper pole of the SBI often do not fit those

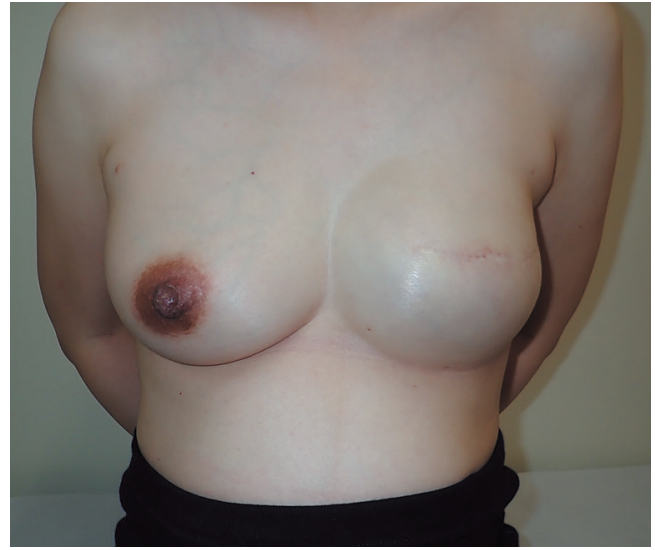

Figure 6 Image at 3 years after silicone breast implant operation in the no-grafting group (age, 35 years; body mass index, $23.3 \mathrm{~kg} / \mathrm{m}^{2}$; volume of silicone breast implant, $570 \mathrm{~cm}^{3}$; medial and median aesthetic outcomes score, 1 and 1 , respectively). The upper edge of the silicone breast implant is visible.

in the upper pole defect of the affected breast. The visible upper edge of the SBI due to the level of differences and depression generally occurs in patients with thin pectoral subcutaneous tissue after mastectomy. Such patients may tend to have superficially invasive mammary carcinomas.

To ameliorate this level of difference and depression in the upper pole of the reconstructed breast, fat injection is often performed (2-5). Fat injection involves harvesting by liposuction of which donor site is generally abdomen or thigh and injecting after purification by centrifugation (2-5). However, this requires donor sites other than the affected chest and effort for performing an additional method. Moreover, trauma to SBI in fat injection should also be considered. Furthermore, the devices for fat grafting are expensive; therefore, they are sometimes unavailable in general hospitals. Fat survival rate, fat necrosis rate, absorption rate, and need for overcorrection in fat onlay-grafting and fat injection are $33-45 \% / 40$ $60 \%$, less than $10 \% /$ less than $10 \%, 55-67 \% / 40-60 \%$, and $220-300 \% / 170-250 \%$, respectively, and additionally fat necrosis often occurs when a larger amount of fat per volume was grafted (9-13).

Dermal fat grafts have also been used for augmentation in head and neck reconstruction or breast reconstruction, and the taking rate was $40-60 \%(1,14,15)$. Although this technique is comparatively simple and requires no special surgical instruments, donor sites other than the affected chest are required. However, our technique includes 
grafting fat that was harvested from the SBI operative field, and this method has not been reported to date.

Our technique caused no infection, hardened fat, or fat lysis in any case and achieved satisfactory aesthetic results. This technique does not require donor sites other than the affected chest and relies on effectively grafting fat; therefore, it is less invasive. Furthermore, this technique is simple, easy, and allows grafting the fat without sutures; therefore, it is less time-consuming and requires no special surgical instruments. In addition, this onlay-grafting is performed under direct vision on the pectoralis major muscle, which is well-vascularized, and the layer of the grafted fat is completely separated from the layer of SBI; therefore, the probability of infection is low, thereby ensuring high safety. By inserting a suction drain without contacting the grafted fat, neovascularization from surrounding tissue is promoted; thus, the percentage of graft take could increase (13).

The limitations of this study and our technique are as follows. Tumor location and invasion may affect the aesthetic outcomes in the upper edge of the SBI. Furthermore, the extent to which affected pectoral tissue is preserved varies, depending on the breast surgeons, which may also affect these outcomes. Two aspects should be considered when performing this technique: first, infection, hardened fat, and fat lysis may occur when the amount of onlay-grafted fat is high. Second, the upper edge of the SBI may remain visible when the amount of onlay-grafted fat is low. As the results of our study showed, much of the fat was not harvested, particularly in lean patients. In such cases, additional fat harvesting in the caudal or lateral chest should be considered. In a further study, we plan to modify this study including patients undergoing injection of fat, which was harvested from the affected IMF.

\section{Conclusions}

We performed fat onlay-grafting at the upper edge of the SBI with the subcutaneous tissue of the IMF of the reconstructed breast as the donor site in implantbased breast reconstruction. Better aesthetic outcomes were achieved in patients who underwent our technique compared to those who did not.

The merits of our technique are that it includes grafting fat in one stage which was harvested from the same operative field as the SBI operation and was discarded before, and it includes simplicity, minimal invasiveness, and safe augmentation. In addition, our technique could make the upper edge of the SBI invisible; therefore, we believe it can contribute to better aesthetic outcomes in SBI-based breast reconstruction.

\section{Acknowledgments}

Funding: None.

\section{Footnote}

Reporting Checklist: The authors have completed the STROBE reporting checklist. Available at https://dx.doi. org/10.21037/gs-21-425

Data Sharing Statement: Available at https://dx.doi. org/10.21037/gs-21-425

Peer Review File: Available at https://dx.doi.org/10.21037/ gs-21-425

Conflicts of Interest: All authors have completed the ICMJE uniform disclosure form (available at https://dx.doi. org/10.21037/gs-21-425). The authors have no conflicts of interest to declare.

Ethical Statement: The authors are accountable for all aspects of the work in ensuring that questions related to the accuracy or integrity of any part of the work are appropriately investigated and resolved. The study was conducted in accordance with the Declaration of Helsinki (as revised in 2013). The protocol for this study was approved by the ethics committee of the Tochigi cancer center (C248). Written informed consent was obtained from the patient for the publication of this manuscript and any accompanying images.

Open Access Statement: This is an Open Access article distributed in accordance with the Creative Commons Attribution-NonCommercial-NoDerivs 4.0 International License (CC BY-NC-ND 4.0), which permits the noncommercial replication and distribution of the article with the strict proviso that no changes or edits are made and the original work is properly cited (including links to both the formal publication through the relevant DOI and the license). See: https://creativecommons.org/licenses/by-nc-nd/4.0/.

\section{References}

1. Hirai R, Kajikawa A, Aihara M, et al. Hybrid Breast 
Reconstruction with Breast Implants and Dermal Fat Graft. Oncoplast Breast Surg 2017;2:91-7.

2. Spear SL, Wilson HB, Lockwood MD. Fat injection to correct contour deformities in the reconstructed breast. Plast Reconstr Surg 2005;116:1300-5.

3. Losken A, Pinell XA, Sikoro K, et al. Autologous fat grafting in secondary breast reconstruction. Ann Plast Surg 2011;66:518-22.

4. Auclair E, Blondeel P, Del Vecchio DA. Composite breast augmentation: soft-tissue planning using implants and fat. Plast Reconstr Surg 2013;132:558-68.

5. Weichman KE, Broer PN, Tanna N, et al. The role of autologous fat grafting in secondary microsurgical breast reconstruction. Ann Plast Surg 2013;71:24-30.

6. Nava M, Quattrone P, Riggio E. Focus on the breast fascial system: a new approach for inframammary fold reconstruction. Plast Reconstr Surg 1998;102:1034-45.

7. Bogetti P, Cravero L, Spagnoli G, et al. Aesthetic role of the surgically rebuilt inframammary fold for implant-based breast reconstruction after mastectomy. J Plast Reconstr Aesthet Surg 2007;60:1225-32.

8. Harris JR, Levene MB, Svensson G, et al. Analysis of cosmetic results following primary radiation therapy for stages I and II carcinoma of the breast. Int J Radiat Oncol

Cite this article as: Ishii N, Harao M, Kiuchi T, Sakai S, Uno T, Ando J, Kishi K. Making the upper edge of a silicone breast implant invisible by fat onlay-grafting harvested from the affected inframammary fold. Gland Surg 2021;10(9):2656-2662. doi: $10.21037 / g s-21-425$
Biol Phys 1979;5:257-61.

9. Coleman SR, Saboeiro AP. Fat grafting to the breast revisited: safety and efficacy. Plast Reconstr Surg 2007;119:775-85; discussion 786-7.

10. Mineda K, Kuno S, Kato H, et al. Chronic inflammation and progressive calcification as a result of fat necrosis: the worst outcome in fat grafting. Plast Reconstr Surg 2014;133:1064-72.

11. Coleman SR, Mazzola RF, Pu LL. Fat injection from filling to regeneration. 2nd ed. Stuttgart: Thieme Medical Publisher, 2018.

12. Billings E Jr, May JW Jr. Historical review and present status of free fat graft autotransplantation in plastic and reconstructive surgery. Plast Reconstr Surg 1989;83:368-81.

13. Peer LA. Transplantation of fat. In: Converse JM, editor. Reconstructive Plastic Surgery. Philadelphia: WB Saunders, 1964:105-16.

14. Schuessler WW, Steffanoff DN. Dermal grafts for correction of facial defects; a series of 80 cases. Plast Reconstr Surg (1946) 1949;4:341-51.

15. Davis RE, Guida RA, Cook TA. Autologous free dermal fat graft. Reconstruction of facial contour defects. Arch Otolaryngol Head Neck Surg 1995;121:95-100. 